\title{
Rituais e símbolos na atenção formal à saúde: o caso do vestuário profissional, na ótica de pacientes da Atenção Básica
}

| ${ }^{1}$ Bruno José Barcellos Fontanella, ${ }^{2}$ Fernanda Rodrigues da Silva, ${ }^{3}$ Romeu Gomes I

Resumo: Este trabalho teve como objetivo analisar e interpretar as reflexões e experiências de usuários frequentadores do serviço de Atenção Primária à Saúde / Unidades de Saúde da Família (USF) sobre o uso do jaleco branco ou roupas brancas por médicos e outros profissionais de saúde. $\mathrm{O}$ método utilizado foi o de entrevistas individuais com questôes abertas, em profundidade, com usuários de USF, transcritas integralmente e analisadas quanto ao conteúdo e enunciados. A amostra foi fechada por saturação teórica. Como resultado, identificou-se nas 11 entrevistas uma marcante assimetria sociocultural e psicológica como pano de fundo dos três núcleos de sentido identificados: vestuário como marca identitária; vestuário não valorizado como símbolo de competência profissional e vestuário interferindo, positiva ou negativamente, nas relações entre clínicos e pacientes. Discutem-se a premência à simbolização na área da saúde, as dificuldades dos participantes em discorrer sobre o tema e sobre o porquê da emergência de possíveis novos símbolos de competência. Finalmente, concluiu-se que compreender os significados atribuídos pelos usuários dos sistemas de saúde aos atos e práticas realizados por seus cuidadores pode contribuir para o aperfeiçoamento progressivo dessas práticas formais de cuidado. Embora as funçôes ritualísticas dos comportamentos e objetos utilizados nos atos de cuidado à saúde sejam mais facilmente observadas nas chamadas práticas informais e populares, elas persistem nas maneiras formais ou profissionais de agir. Esse tipo de fenômeno se deu após a emergência da medicina científica moderna, com o jaleco branco, por exemplo, e ainda se dá, na atualidade, embora novos símbolos pareçam surgir e ocupar esse espaço ritualístico.

> Palavras-chave: relações profissional-paciente; relações médicopaciente; vestuário; antropologia; comportamento ritualístico.
1 Professor adjunto do

Departamento de Medicina (Área de Saúde Mental) do Centro de Ciências Biológicas e da Saúde da Universidade Federal de São Carlos. Endereço eletrônico: bruno.fontanella@ gmail.com

2 Estudante de graduação do Curso de Medicina da Universidade Federal de São Carlos. Endereço eletrônico: fer_rodriguesilva@hotmail.com

${ }^{3}$ Pesquisador titular do Instituto Fernandes Figueira da Fundação Oswaldo Cruz (IFF-FIOCURZ). Endereço eletrônico: romeu@ iff.fiocruz.br
Recebido em: 21/10/2010. Aprovado em: 21/04/2011. 


\section{Introdução}

Alguns dos signos presentes nos atos de cuidado à saúde repetem-se, são aconselhados, indicados ou mesmo normatizados, porém não têm funções técnicas precisas e tampouco produzem resultados tecnológicos facilmente objetiváveis. Têm significados principalmente simbólicos e funções ritualísticas (LOUDON, 1966), sendo, por vezes, difundidos em diferentes sociedades, atravessando diversas gerações e épocas.

Esse parece ser o caso do vestuário típico dos profissionais de saúde, os jalecos e outras roupas brancas. Apesar do uso tão propagado, não foram encontradas referências a estudos sobre os significados simbólicos do uso desse vestuário na base de dados LILACS e na biblioteca SciELO. Pareceu-nos justificável, então, iniciar uma exploração desse tema no sistema formal de saúde pública brasileiro, particularmente no atual momento da história de sua organização, em que os gestores públicos procuram expandir a cobertura da Atenção Básica por meio da Estratégia de Saúde da Família.

Há registros iconográficos do uso desse tipo de indumentária desde o final do século dezenove, no advento das ciências médicas modernas e do modelo biomédico de exercício clínico. Tal modelo promoveu uma configuração das relações entre médicos e pacientes diferente daquela praticada até então (BURY, 2001), e, ao que nos parece, não por uma coincidência casual, essas relações teriam passado a ser intermediadas simbolicamente por um anteparo físico.

$\mathrm{O}$ uso do jaleco branco começou nos ambientes laboratoriais, por razões práticas de proporcionar uma barreira física com os objetos de trabalho (KAZORY, 2008). A partir daí, teria passado a ser um costume também na área clínica, que progressivamente incorporava os conhecimentos biomédicos e seu então recente status de cientificidade (JONES, 1999). O uso da cor branca, nesse mesmo contexto clínico, tem sido registrado também desde o final do século XIX (CALLEGARI, 2004), com prováveis conotaçōes de pureza e limpeza (KAZORY, 2008). Passado mais de um século, o simbolismo do uso do jaleco branco persiste, marcando, inclusive, por meio das "white coat ceremonies" de algumas escolas médicas, a transição curricular da fase pré-clínica para a fase clínica (JONES, 1999). 
Tacitamente, o jaleco é geralmente justificado como uma medida de biossegurança e como meio de facilitação da relação entre clínicos e pacientes, embora os principais livros de medicina interna e de semiotécnica sequer abordem tais assuntos. Sabe-se que é possível, na verdade, facilitar a veiculação de microrganismos (LOH; NG; HOLTON, 2000) e, sob esse argumento, algumas sanções ao seu uso já são verificadas (EDITORIAL, 2007).

Sobre facilitar ou não a relação clínico-paciente, os achados comentados na literatura são conflitantes, parecendo variar os significados desse objeto nos diferentes contextos culturais pesquisados. A maioria dos pacientes seria indiferente ou preferiria que os clínicos não usassem o jaleco (NEINSTEIN; STEWART; GORDON, 1985; MENAHEM; SHVARTZMAN, 1998; FISCHER et al., 2007). Em outros estudos, o uso foi considerado desejável pela maioria dos pesquisados (DUNN et al., 1987; GOODEN et al., 2001; BUDNY et al., 2006), sobretudo por crianças (BUDNY et al. 2006) e idosos (MENAHEM; SHVARTZMAN, 1998). Quanto aos próprios médicos, as gerações mais recentes e os estudantes de medicina tenderiam a não valorizá-lo (WATSON, 2002; GJERDINGEN; SIMPSON; TITUS, 1987).

Tendo em vista o exposto, consideramos importante tentar compreender alguns dos significados que os usuários atribuem a alguns comportamentos dos profissionais que os assistem, e com os quais poderão ter uma relação profissional de longo prazo, favorecendo ou não o cuidado longitudinal, aspecto particularmente valorizado nos contextos da Atenção Primária à Saúde. Neste trabalho, nosso foco foram os significados do uso do jaleco ou outras roupas brancas.

\section{Método}

O método, as técnicas e os procedimentos empregados foram qualitativos, consoante à natureza do objeto estudado (significados simbólicos). Foi considerada, em particular, a literatura especializada no aparato metodológico qualitativo no campo da saúde (MINAYO, 1993; MORSE; FIELD, 1995) e no contexto clínico (TURATO, 2003), procurando-se valorizar aspectos experienciais e representacionais relacionados ao processo saúde-doença (GOMES; MENDONÇA, 2002). 
O campo de estudo compreendeu três Unidades de Saúde da Família (USF) de um município do interior paulista às quais a entrevistadora tinha acesso como estudante de medicina. O principal critério de inclusão de participantes foi um histórico de vinculação institucional com a USF de pelo menos seis meses e, portanto, supostamente, uma suficiente aculturação à problemática investigada. Todos os participantes assinaram um Termo de Consentimento Livre e Esclarecido aprovado pelo Comitê de Ética em Pesquisa com Seres Humanos de uma das instituições a que os autores se filiam.

O fechamento da amostra intencional foi tecnicamente feito por saturação teórica, interrompendo-se a captação de novos participantes quando as entrevistas individuais realizadas foram julgadas suficientes para sustentar empiricamente o desenvolvimento de novas reflexões sobre o tema (GLASER; STRAUSS, 1967; FONTANELLA; RICAS; TURATO, 2008). As entrevistas foram feitas entre maio de 2008 e julho de 2009.

Um tema principal foi proposto aos participantes: "O que você pensa sobre o uso de jaleco ou outras vestimentas brancas pelos médicos e outros profissionais de saúde?”. Alguns subtemas foram ativamente introduzidos, caso não abordados espontaneamente: possíveis motivos para o uso; preferências pessoais do participante; por que o branco seria a cor mais usada; influência do vestuário na relação com o paciente; variações quanto aos diferentes tipos de serviços, especialidades e profissóes. $\mathrm{O}$ fraseado das questôes foi adaptado, à medida do possível, ao universo sociocultural e educacional de cada entrevistado.

$\mathrm{O}$ áudio das entrevistas foi gravado digitalmente e integralmente transcrito. Depois de familiarizados com a leitura desse corpus, os pesquisadores procederam a uma análise de conteúdo nas modalidades temática e de enunciados (MINAYO, 1993; BARDIN, 1979) e circunscreveram os achados em algumas categorias, de acordo com a identificação de núcleos de sentido nesses enunciados. Procurouse manter uma postura de atenção constante aos pormenores e ao corpus como um todo, em busca de validade interna dos achados, ou seja, da presença de uma consistência empírica suficiente para uma discussão teórica considerada relevante.

\section{Resultados}

Foram realizadas 11 entrevistas, que totalizaram um corpus transcrito de cerca de 25 mil palavras. O quadro 1 expõe algumas características sociodemográficas da amostra (os entrevistados são identificados por letras). 
A - Masculino; 62; segundo grau incompleto; agricultor; branco; casado; 4 filhos; católico não praticante; diagnóstico de hipertensão arterial sistêmica.

B - Feminino; 28; segundo grau completo; dona de casa; negra; casada; 3 filhos; evangélica praticante; diagnóstico de labirintopatia.

C - Feminino; 49; ensino fundamental completo; dona de casa; negra; viúva; 1 filho; evangélica praticante; diagnóstico de hipertensão arterial sistêmica e diabetes mellitus tipo 2 .

D - Feminino; 20; segundo grau completo; dona de casa e vendedora autônoma; branca; casada; 1 filho; católica praticante; diagnóstico de asma.

E - Feminino; 76; ensino fundamental incompleto; dona de casa aposentada; branca; viúva; 3 filhos; católica praticante; diagnóstico de hipertensão arterial e diabetes mellitus tipo 2 .

F - Feminino; 22; segundo grau completo; dona de casa; não soube responder a etnia; casada; 1 filha, católica não praticante; diagnóstico de lesão por HPV.

G - Feminino; 53; ensino médio; agente de serviço escolar; branca; casada; 1 filho; sem problemas de saúde identificados.

H - Feminino; 26; ensino superior; engenheira florestal; branca; solteira; 1 filho; católica praticante; acompanhamento na USF por gestação e puerpério .

I - Feminino; 28; ensino superior incompleto; professora; parda; casada; 3 filhos; católica praticante; sem problemas de saúde identificados.

J - Feminino; 61; ensino fundamental incompleto; dona de casa; branca; casada; 2 filhos; católica praticante; diagnóstico de hipertensão arterial sistêmica, diabetes mellitus tipo 2 e artrite reumatóide.

K - Masculino; 26; superior incompleto; estudante; branco; solteiro; sem filhos; "monoteísta"; diagnóstico de rinite alérgica.

A partir do andamento observado em algumas entrevistas, com respostas que tendiam a ser curtas, supõe-se ter havido dificuldades de alguns participantes de se estenderem sobre o tema - tendo a entrevistadora proposto ativamente os subtemas para a maioria dos participantes.

\section{Assimetria da relação clínico-paciente como contexto das significações}

Os núcleos de sentido identificados nas entrevistas se assentaram, segundo nossa avaliação, em marcantes assimetrias socioculturais e psicológicas entre os participantes e seus clínicos, permitindo inferências de quatro "eixos" de polarização (quadro 2). 


\section{Diferentes formas de conhecimento sobre o processo saúde-doença ("disease" $X$ "illness")}

"A saúde está cada vez mais complexa, com doenças [...]. Os cientistas trabalham sempre para o futuro, eles estão vendo que as doenças estão piores [...]. Como a maioria mora na área rural, eles não têm contato com a rotina da unidade e com os hospitais, pensam dessa maneira. Eles precisam de mais informação de como as coisas funcionam para entenderem. Pela falta de informação, algumas pessoas chegam até a passar mal diante dos médicos e dos aparelhos para os exames. Assim, é melhor os médicos estarem vestindo uma roupa normal, no máximo com jaleco." [C]

"Tava com muita dor, chorava demais [...] ele passou no pediatra e tava com os dois ouvidos infeccionados. [...] Meu filho ficou doente de novo e foi internado. Aí descobriu que era bronquite. [...] Fiz o pré-natal lá, fui pra maternidade ter os meninos. Aí lá na maternidade eu fiquei ruim porque me deu sede e me deram água gelada, tava trincando, e eu bebi, apaguei, né?, apaguei.” [B]

\section{Identificação de pertenças a diferentes estratos socioeconômicos}

"A população aqui diz que o médico tem que ta igual a ela porque, se não, não se sente à vontade. Assim, a roupa interfere muito na relação médico-paciente, principalmente aqui, em que [sic] as pessoas pensam diferente. Acho que pensam assim porque moram mais longe do centro urbano." $[\mathrm{C}]$

"Se você vê uma pessoa de branco, tem respeito por ela, por ser médico e ter uma condição de vida melhor. Mas o respeito também é do médico pelo paciente." [G]

"Acho sim que eles têm que se igualar, porque tem pessoas... me falam que só de estarem perto, de chegarem no médico, eles não conseguem conversar... pode ser essa questão de eles acharem que o médico está em outro patamar, mas eu acho que realmente eles têm que ter uma identificação diferente, eles são médicos. Por mais, é claro, que tem [sic] que se aproximar da população... mas não tem como se igualar." [J]

\section{Assimetria relativa a quem sofre as angústias do agravo à saúde}

"A pessoa numa situação de estresse muito forte [...] e ela vê uma pessoa de branco, já caracteriza associar isso a um médico, uma pessoa que vai manipular a vida dessa pessoa, e talvez isso gera [sic] uma confiança, não sei, maior tranquilidade, que ela fala que agora pode estar mais segura." [K]

\section{Polos decorrentes do processo de objetivação da doença}

"Fiquei internada quando tinha 48 anos, naquela fase de parar a menstruação. Aí o médico falou que eu tava com mioma e precisava fazer cirurgia. Fiz a cirurgia, tirei apenas o mioma e o médico falou que eu sou normal. [...] Isso foi bom pra mim porque descobriram o que eu tinha e me operaram." [E]

"A gente passou aí no posto. O que eu tinha, que ele não sabia, ele passa pro [outro médico]. Ele pega o prontuário, vê tudo o que eu preciso" [I] 
$\mathrm{O}$ primeiro eixo diz respeito às diferentes formas de conhecimento sobre o processo saúde-doença-cuidado. Polarizam-se ao seu redor a visão leiga das práticas populares em saúde e os conhecimentos dos profissionais.

Um segundo eixo refere-se à identificação, por parte dos entrevistados, de pertença a um estrato social diferente dos que ocupam o polo profissional da relação. No quadro 2 há exemplos da ideia de “igualar” os componentes da relação - o que mostra uma visão apriorística de desigualdade. O suposto domínio dos profissionais de conhecimentos científicos e de recursos tecnológicos pareceu também servir aos participantes como um indicador de pertencimento a estratos sociais mais elevados.

O terceiro eixo diz respeito a quem ocupa, no encontro pacienteprofissional, o papel de quem sofre as angústias relacionadas ao agravo à saúde. Mesmo que podendo ser vistas como compartilhadas empaticamente com o profissional, tal lugar foi, como esperado, visto pelos participantes como ocupado por eles próprios.

Por fim, um quarto eixo que estruturaria a assimetria das relações diz respeito aos polos decorrentes do processo de objetivação da doença. Aparentemente, os entrevistados se alternaram nas posições de serem objetivados (à medida que "portam" a doença) e de objetivadores (quando assumem, como seus, o discurso das ciências médicas e da saúde).

\section{Jaleco branco como marca identitária}

Perguntados sobre o que pensam sobre os jalecos e outras roupas brancas, os entrevistados referiram-se a esse vestuário, em geral com imediatismo, como marcas identitárias. A despeito de os entrevistados desejarem ou não que seja assim, o sentido mais facilmente explicitável pareceu claro nas entrevistas: indicaria a presença de pessoa em exercício de uma profissão do setor saúde.

Talvez a designação semiótica mais correta desta indumentária seja a de tratarse de um icone desse setor profissional, dada a unanimidade dessa significação, pelo menos na amostra estudada. $\mathrm{O}$ quadro 3 expõe exemplos. 


\begin{abstract}
"Só essa roupa branca que tá persistindo, até a farda [militar] já mudou várias vezes e o branco continua insistindo na medicina [...] Se fosse em um laboratório, em um lugar de experiência, que a pessoa vai lidar com produtos químicos, que não tem contato com o povo, que é uma coisa ali dentro, acredito que ali não tem nenhum motivo pra mudanças, o interesse é sempre, não um uniforme, mas um protetor pra não sujar a roupa praticamente.” [A]

"Porque com o uniforme dá pra perceber de longe: “Ah, aquilo lá é uma enfermeira, aquilo lá é um médico", então isso é importante. [...] Acho que é uma rotina da própria medicina. Algo escolhido há muito tempo pelos superiores. Penso que escolheram o branco porque representa paz e se destaca mais. De longe pode-se dizer que aquele lá é médico. [...] A cor muda pra não ter confusão. A gente consegue saber que aquele lá é um cirurgião. E já é um costume, isso." [B]

“[...] em primeiro lugar eu penso que é uma maneira de diferenciar eles das demais pessoas, e aí você pode identificar quem é quem da área da saúde. [...] Você consegue distinguir quem faz parte de cada grupo, então tem que ter a diferenciação. Aqui na unidade, a diferenciação é assim: os estudantes estão sempre de jaleco; a enfermeira usa apenas a roupa branca; os agentes usam o verde [...], senão, você não vai saber quem é do centro cirúrgico, quem é do laboratório, quem é da farmácia. Se cada setor tem a sua cor, você já sabe. Fica mais fácil pro usuário. Além de diferenciar, facilita a identificação e a comunicação." [C]

“[...] eu acho que mostra que é um profissional que trabalha na área da saúde. Isso faz diferença.” [D]

“A roupa branca facilita o médico na postura, já está ligada a roupa branca à profissão, mas eu não vejo necessidade. Uma coisa assim, que tenha que ser o branco, eu acho que não... [...] Eu acho que também tem um pouco de postura profissional, alguns acreditam que isso esteja relacionado com uma postura, colocar um jaleco e sentir um pouco mais médico (risos).” [H]

"Se você entra num hospital e vê um de cada cor ali, você nem vai saber quem é quem. Se é uma pessoa de branquinho, bonitinho, você sabe que aquela é médica, enfermeira, é uma assistência e tudo...” [I]

“[...] por já ter provavelmente mais de 100 anos que eles usam o jaleco branco, eu acho que imediatamente você vê o jaleco e associa com medicina, é uma coisa imediata, tanto que você fala médico, aqueles carinhas de branco, você já associa isso. E já se tornou uma linguagem universal..." [K]
\end{abstract}

Algumas especificações desse tipo de significação foram percebidas nas mençōes dos participantes às distinções facilitadas pelo vestuário: profissionais $\mathrm{X}$ não-profissionais, profissionais X estudantes, médicos $\mathrm{X}$ outros profissionais $\mathrm{e}$ também entre os diferentes tipos de exercício profissional, de acordo com o cenário assistencial em que ocorrem.

\title{
Vestuário como indicador (porém não como ícone) de competência
}

A despeito de identificarem o exercício profissional, os significantes jaleco e outras roupas brancas não pareceram corresponder de modo imediato, na fala 
dos participantes, ao atributo de competência profissional. A identidade de que esse vestuário pareceu servir como ícone seria antes a de um detentor do direito legal de exercer uma profissão da saúde, ou seja, uma espécie de identificador de certificação profissional.

Os dados coletados não permitiram inferir que o vestuário seja uma marca identitária forte de como (ou mesmo se) a competência associada à profissão seria exercida. Em outras palavras, o vestuário não designaria, para os participantes, ao menos necessariamente, estarem diante de alguém em efetivo exercício clínico, entendido como a função reconhecida e legitimada historicamente e socialmente de observar, avaliar, tratar e cuidar de um paciente. Do mesmo modo como enfatizaram esse tipo de identidade profissional, com a mesma ênfase os entrevistados destacaram que poderiam facilmente prescindir desse tipo de marca.

Como também exemplificado No quadro 4, outros tipos de símbolos de competência médica (carimbos, solicitação de exames, postura respeitosa, não prescindir do exame físico) parecem emergir na amostra estudada.

\section{Quadro 4. Exemplos de frases dos participantes sobre o vestuário ser um indicador (mas não ícone) de competência profissional}

\footnotetext{
"A roupa não vai rogar em nada. O que conta para o paciente são os procedimentos e a maneira como o médico se porta. [...] Mas a gente conversa, aí vem a receita, aí na receita que você vai ver que carimbou, ali tá no nome de um médico, você já sabe, fica com um pouquinho do pé atrás na hora que você entra, mas, depois, se alivia na hora que ele assina lá, carimba lá e tá o nome dele” [B]

"Isso sei lá, o governo... mas toda a vida que eu me conheço como gente, sempre foi branco. [E, sobre se o vestuário branco pode ser trocado] Acho legal que use, mas se não estiver, não vou reclamar por isso." [F]
}

"Desde que ele seja competente, o jaleco não vai fazer nada. Quando ele se interessa e aprofunda mais é diferente. E eu percebo que é um médico. Quando o médico diz para deitar, que vai examinar e pedir alguns exames, que vai procurar o que pode ser para depois passar medicamento e você sente que ele se interessou..." [G]

"Você acaba vendo a credibilidade da pessoa, independentemente da roupa que ela está. [...] Acho que para o atendimento de um consultório, uma coisa que seja um pouco mais simples. [...] Se você vai num hospital, você vai lá dentro e está sem uma máscara, sei lá, com o cabelo solto, acho que é um pouco de desleixo." [H]

"Ah... dá um significado, que a pessoa... dá outro respeito. [...] Eu não faço questão nenhuma, eles atendem a gente tão bem com a roupa ou sem. A gente sendo bem atendido, tanto faz, tanto fez. [...] Foi um médico atender ele e tava com uma roupa assim, calça e camisa normal. Pra mim, não significou nada [mas] depois que ele saiu, meu marido falou: 'quem é esse?'. Aí eu disse que era o médico. [...] Vai acabar esse negócio de ter o branco.” [I] 
"E o que passa a responsabilidade é o contato com o paciente, pôr a mão, mesmo, no paciente. Eu já passei por isso, então eu acho que o contato mesmo com o paciente, colocar a mão, conversar, isso pra mim é muito importante." [J]

"Eu acho que, talvez pela tradição, eu creio que todo mundo se sente mais à vontade quando vê uma pessoa de branco. Ficou tão embutido na cultura, não sei no oriente, mas no ocidente, a vestimenta branca ser do tratamento da medicina, que as pessoas, no geral, olham e vão falar que ali tem um médico e que é um local de confiança, vai sentir, pensar que talvez ali vai [sic] arrumar a cura para o seu problema." [K]

\section{O jaleco e outras roupas brancas e a relação profissional-paciente}

Embora aparentemente prescindível quanto ao uso, o jaleco e outras roupas brancas parecem ainda associar-se, na amostra estudada, a atributos relacionados à atenção à saúde. Ideias relacionadas à limpeza e à proteção física (quanto à contaminação) foram explicitadas. Estar asseado, demonstrando isso pelo vestuário utilizado, mostraria boa vontade do profissional para atender. Como contraponto, um entrevistado associou-o ao não cuidado (quadro 5).

Alguns elementos da esfera da afetividade do profissional estariam representados pelo vestuário. No quadro 5 encontram-se menções a "gosto por atender", "obediência" (no sentido de não anomia no exercício da prática clínica), "disciplina" e "pureza". Do mesmo modo, elementos afetivos próprios dos participantes seriam suscitados pelo jaleco branco, como o "medo" e "respeito" pelo profissional.

\section{Quadro 5. Exemplos de frases dos participantes sobre como vestuário profissional interfere na relação clínico-paciente}

\footnotetext{
"Não sei se é devido à idade, há um certo trauma de saber que você vai naquele lugar encontrar aquele pessoal tudo de branco. [...] Porque parece que quando você vai indo pro branco, parece que você vai indo pra morte. Mesmo sabendo que você vai indo se cuidar... dá a impressão que é ao contrário. [...] É um medo que eu sinto, acho que é relativo como eu disse pra você, medo de doença, de... não sei [...] mas eu sinto aquele mal estar, aquela coisa na hora quando eu chego no centro ali...” $[\mathrm{A}]$

"Os uniformes devem estar sempre arrumados, limpos, bem passados, com tudo em cima. Se não for assim, a gente tem a ideia de pouco caso, de que não estão trabalhando com vontade, com gosto naquilo que ele escolheu para fazer. [...] Se estiverem totalmente de branco, é pânico na certa, eles já não querem mais deixar o médico cuidar deles." [C]

"Acho que nem todos os médicos gostam de usar o branco, mas eu acho que o uso indica respeito, profissionalismo por parte deles.” [D]

"A roupa branca é mais prática, e você bate o olho e já vê que está suja. Mostra limpeza. [...] O médico da minha filha, por exemplo, não usa o jaleco no consultório, só quando ele vem atender nas unidades." [E]
} 
"Acho que protege a roupa, você vem e sempre tá bem vestida, que está limpa, sem sujeira. [...]

Acho que para as crianças sim. Minha filha [...] já estranha quando vê uma pessoa de branco. Ela sempre tem que tomar medicamento, fazer exame de sangue e uma pessoa de branco assusta ela. Até para ver a garganta na consulta ta ficando difícil.” [F]

"Eu acho que o jaleco é muito importante, principalmente para a parte higiênica de manipulação, de contato com as pessoas. [...] Se o profissional estiver com outra roupa, pode ser mais fácil a comunicação." [H]

"Quando ele ta de branco parece passar mais responsabilidade, você tem mais confiança naquele médico, naquela enfermeira. Quando está com uma roupa normal que não seje [sic] branco, você fica cismado. [...] Ah, eu relaciono como mais responsabilidade. Dá um ar de mais responsabilidade, o branco, quando o profissional está de branco. [...] O jaleco, acho que seria uma proteção, porque suja [...] Agora, em questão com criança, eu acho que atrapalha um pouco. A criança já vê aquilo e sente um medo, ou coisa assim." [J]

"O branco me dá uma sensação imediata de limpeza [...]. Você consegue ver o que tá na roupa, se ela foi bem cuidada... Você imagina: se a roupa é bem limpa, o profissional também é uma pessoa bem organizada. Agora, se na roupa tem umas bordas, assim, você fica meio com o pé atrás com a pessoa, porque, afinal, ela vai estar te manipulando [...] e se a pessoa tem alguma coisa que possa contaminar, ele pôs o jaleco e usou uma microbarreira, não sei se isso é só psicológico ou se realmente protege, não chega a contaminar a roupa dele e seria melhor até pra ele. [...] Uma pessoa que esteja com muita dor e desesperada por tratamento, a hora que ela chega no ambiente e vê aquelas pessoas de branco, talvez só isso já possa ela ajudar a se aliviar da dor, porque eu acho que parte da dor é emocional, e você aumenta a dor, e saber que lá ela será tratada pode deixar mais aliviada. [...]” [K]

Houve menções a uma possível facilitação do início da relação profissionalpaciente, em razão de o jaleco identificar o profissional e as diferenças de comportamentos nos serviços público e privado.

\section{Discussão}

\section{Premência à simbolização}

A necessidade humana de gerar sentidos/significados decorre, em última instância, da polarização eu-mundo, e, no caso do presente objeto de pesquisa, esses significados teriam tido suas expressōes catalisadas por tensões resultantes de um encontro paciente-cuidador marcado por disparidades e assimetrias. A explicitação das assimetrias socioeconômicas foi facilitada, aparentemente, pelo contexto assistencial das entrevistas, já que os usuários das USF correspondem ainda hoje aos estratos mais baixos da população brasileira. Porém, estariam em jogo também um forte antagonismo cultural entre clínicos e pacientes nos modos de interpretar o processo saúde-doença-cuidado, além de potenciais e intensas angústias, vividas, sobretudo, pelos pacientes, o que pode explicar a busca por significações de competência clínica. 
O último eixo gerador de assimetrias (alternância do lugar ocupado pelos entrevistados no processo de objetivação da doença, ora objetivadores, ora objetivados) parece-nos particularmente importante, à medida que alguns participantes pareceram procurar preencher uma função objetivadora "especializada", comportamento esperado, a priori, dos profissionais.

Como exemplificado em frase do quadro 2, uma das entrevistadas [C] discorreu sobre considerar que o grau de "informação" do paciente interferiria na ideia que ele faz do branco. Para ela, o vestuário branco, típico dos médicos, seria associado a medo e aversão por parte de pessoas sem "contato com a rotina da unidade", sugerindo inclusive uma espécie de tecnofobia de parcela da população. Para compreender "o porquê da importância de usar o branco" [C], ou seja, não se constranger diante de alguém vestido assim, o paciente deve, em sua opinião, ser mais bem informado, exemplificando que os habitantes do meio rural teriam maiores dificuldades e temeriam os médicos e outros profissionais da saúde. Defrontar-se com um profissional da saúde de maneira menos ansiogênica demandaria, segundo a participante, familiaridade com a ciência e tecnologia médicas, de modo a identificar "corretamente" o jaleco branco como um símbolo do exercício de tecnologias "benéficas", e não o contrário.

Uma explicação correlata pareceu fundamentar a constatação de alguns informantes de que as crianças seriam negativamente sensíveis a um profissional vestido de branco. Como se, por incapacidade de compreender, ou por uma compreensão incorreta, o significado preponderante pudesse passar a ser "perigo", gerando medo. Curiosamente, essa suposição dos entrevistados se contrapóe a alguns achados da literatura sobre a reação das crianças ao jaleco branco (MATSUI; CHO; RIEDER, 1998).

\section{Um tema difícil para os informantes}

Uma das possibilidades levantadas para explicar o laconismo de alguns entrevistados é a dificuldade de imaginarem que algumas práticas formais de cuidado à saúde possam ter significados simbólicos. Assim, alguns entrevistados restringiram-se inicialmente a expor significações de caráter denotativo: como disse uma entrevistada, "branco é branco". A medicina (profissão mais tradicional e característica dentre as que se ocupam da saúde) apenas há poucas gerações entrou na chamada "era científica". Apesar disso, ela já não parece comportar facilmente representações de utilizar-se de um aparato ritualístico, não tecnológico. 
Outra possibilidade interpretativa para as entrevistas de andamento aparentemente mais truncado ampara-se nas já referidas posições marcadamente assimétricas ocupadas pelos clínicos e pacientes. Alguns constrangimentos para falar podem ter decorrido dessas assimetrias: a entrevistadora pode ter sido identificada como representante do outro polo em questão.

\section{Competência clínica $\mathrm{x}$ certificação}

O vestuário branco não foi, em geral, valorizado pela amostra como importante per se - tendo sido, ao contrário, repetidamente desvalorizado e referido como dispensável, em função do atributo da competência clínica, esta sim valorizada pelos participantes. A desvalorização do jaleco branco vai ao encontro de outros estudos recentes que sugerem também essa tendência nas preferências dos pacientes sobre o vestuário dos clínicos (LILLl; WILKINSON, 2005). A razão que levaria ao uso desse vestuário foi relacionada a fatores prosaicos como moda, conforto, atenção a regras burocráticas e tradições (cujas origens os entrevistados referiram desconhecer) ou mesmo o branco como uma espécie de incentivo psicológico positivo para o profissional manter-se higienizado (sendo supostamente mais fácil identificar sujidades, o profissional logo se trocaria). Foi também comentado pela amostra o que pode ser descrito como dinamicidade histórica e geográfica dos significados, tendo sido constatado o uso, relativamente mais recente, de outras cores "neutras" ou "frias", como o verde, o azul e o rosa claros, em alguns ambientes específicos.

Desse modo, mesmo sendo possível prescindir do jaleco e outras roupas brancas como significantes do cuidado, os elementos da amostra forneceram indícios de que alguns "significantes emergentes" começam a carregar consigo esse significado historicamente tão valorizado e reiteradamente afirmado como importante pelos participantes. Dentre eles, foram mencionados o carimbo do médico numa receita, a solicitação de exames laboratoriais e as habilidades propedêuticas/semiológicas (anamnese e exame físico).

Uma questão que se coloca a partir desses achados é: por que estaria havendo essa mudança dos símbolos de competência clínica? Cogita-se que, na primeira metade do século XX, quando o uso do jaleco branco pelos profissionais de saúde aparentemente se consolidou internacionalmente (FARRAJ; BARON, 1991), as duas identidades ("profissional da área" e "profissional competente") fossem altamente superpostas. 
No entanto, em que pese à medicina manter atualmente um elevado status sociocultural em relação às demais profissões, seria crescente certa trivialidade da presença dos médicos e outros profissionais de saúde na vida das pessoas, se comparado o momento atual com o de cem anos atrás. Adicionalmente, estaria ocorrendo uma "desglamourização" da profissão médica em função da quebra da hegemonia de seu discurso em relação às questões de saúde-doença, ao crescente controle da sociedade sobre as práticas de saúde (BURY, 2001) e provavelmente em função da maior dinamicidade de veiculação pela mídia de conteúdos informativos sobre saúde (incluindo de atos interpretados como erros médicos). É possível, então, que símbolos mais óbvios e "desgastados" passem a ser preteridos em função de outros.

Fenômenos sociais como esses, associados às próprias experiências pessoais dos entrevistados, provavelmente se relacionam a um descolamento das duas identidades antes superpostas: "ser um profissional certificado" não significaria mais, necessariamente, "ser competente". Para a amostra, pelo que se pôde inferir, portar um jaleco ou apresentar-se de branco, num ambiente assistencial, não significaria muito mais do que mostrar-se como alguém institucionalmente reconhecido: uma espécie de cartão ou crachá de identidade.

\section{Possíveis novos símbolos de competência clínica}

Outra questão que se coloca a partir dos achados é: o que fundamentaria o surgimento ou a utilização desses novos significantes, possíveis novos símbolos profissionais?

À primeira vista, chama a atenção que dois dos novos significantes mencionados (carimbo em receita e solicitação de exames subsidiários) relacionam-se ao processo de tecnologização crescente do setor saúde. Chama também a atenção que dois deles (solicitação de exames e habilidades propedêuticas) são significantes complexos e não puramente visuais, como é o vestuário.

No conjunto, eles parecem referenciar-se não somente a um aparato tecnológico denso, mas compor uma mescla de tecnologias ditas leves, levesduras e duras (MERHY, 2000). Ou, em outras palavras, os novos significantes parecem referir-se ao que se entendia originalmente por techne, a sabedoria no sentido de saber-fazer metódico ou de saber encontrar o que convém em determinada situação; ou, mais precisamente, por klinike techne, algo como o 
ofício ou a arte de assistir pessoas necessitadas de ajuda (excluindo a metonímia original da expressão, referente a pessoas acamadas). Assim, as menções a atos considerados de destreza semiológica (incluindo a semiologia armada, no caso dos exames) podem ser vistas como menções a essa techne milenarmente reconhecida.

\section{Conclusão}

Os dados coletados permitem formular a hipótese de que o jaleco, apesar de marca identitária, tende a não mais indicar competência profissional, mas somente uma certificação burocrática (algo como "é médico" mas não, necessariamente, "é médico competente para cuidar de mim”). Porém, à medida que a antinomia dos encontros paciente-profissional levaria à premência, de ambas as partes (mas particularmente dos pacientes), de se situarem em relação ao outro, foi constatada a utilização de outros símbolos para marcar suas respectivas posições. Em razão do caráter desses encontros, potencialmente permeados por angústias relacionadas às avaliaçôes clínicas "científicas" e precisas, os entrevistados mostraram valorizar outros signos que pudessem conotar a almejada "competência" para diagnosticar, prognosticar e tratar.

Esse primeiro olhar sobre os dados nos aponta para uma polissemia acerca do jaleco branco. O espectro de significados encontrados não é necessariamente consenso interno entre os sujeitos. Ao contrário, em certo sentido, podem divergir entre si. Essa constatação pode servir para argumentar que, embora os significados sejam culturalmente construídos e partilhados por sujeitos que integram uma mesma rede semântica, eles são subjetivados por aqueles que deles fazem uso.

Embora as funçóes ritualísticas dos comportamentos e objetos utilizados nos cuidados à saúde sejam mais facilmente evidenciadas nas chamadas práticas informais e populares, elas permanecem presentes nas maneiras formais ou profissionais de agir na atenção à saúde. Isso persistiu (por exemplo, com o jaleco branco) após a emergência da medicina científica moderna e, na atualidade, novos símbolos parecem despontar e ocupar esse espaço ritualístico. Tais ocorrências são de estudo ainda mais instigante, por, à primeira vista, se contraporem ao movimento das práticas baseadas em evidências.

$\mathrm{O}$ uso de um anteparo físico entre clínicos e pacientes (à maneira dos trajes dos "médicos da peste" do século XVII), talvez não mais se justifique tacitamente pela lógica da barreira à contaminação, uma vez que as doenças infecciosas 
deixaram de ser o leitmotiv das intervenções médicas, lugar hoje ocupado pelas doenças crônico-degenerativas. Elas têm exigido uma abordagem profissional de mais longo prazo, e que inclui uma atualização da importância das narrativas dos pacientes sobre seus próprios problemas de saúde (BURY, 2001), algo que se opõe, portanto, ao segundo argumento tácito para justificar o uso do jaleco (suposta melhoria da relação clínico-paciente). Desse modo, um símbolo cujo significante é uma barreira/anteparo tenderia a permanecer apenas em contextos clínicos muito específicos e talvez viesse a se configurar futuramente como datado, pertencente à emergência da medicina científica moderna, episteme consolidada no século XX e que talvez, à época, necessitasse de significantes inquestionáveis.

Nesta linha interpretativa, os novos símbolos identificados no corpus viriam a se juntar a outros pouco evidentes, de materialidade ainda menor, porém aparentemente muito presentes no contexto de cuidado à saúde. Dentre eles, pensa-se no código linguistico comumente utilizado pelos profissionais mais graduados (jargão) e acompanhado de um código comportamental (impostação da voz, postura física, expressões fisionômicas, modo de se dirigir ao paciente, a etiqueta nos ambientes de cuidado, etc.).

A presente pesquisa tem as limitações de generalização dos estudos qualitativos, servindo antes à exploração científica de uma questão e ao levantamento de hipóteses. Estudos epidemiológicos que traduzam numericamente a ocorrência dos diferentes significados poderão dela se beneficiar. Profissionais e gestores do setor saúde podem, entretanto, considerar nossos resultados em suas posturas de estímulo ou não ao uso do jaleco e outras roupas brancas. ${ }^{1}$

\section{Referências}

BARDIN, L. Análise de conteúdo. Lisboa: Edições 70, 1979. 281p

BUDNY, A.M. et al. The physician's attire and its influence on patient confidence. J Am Podiatr Med Assoc, v.96, n.2, p.132-138, 2006.

BURY, M. Illness narratives: fact or fiction? Sociol Health Illn, v.23, n.3, p.263-285, 2001. CALLEGARI, D.C. O uso do branco por médicos. Jornal do CREMESP, v. 28, n. jul-set, 2004. Disponível em: <http://www.cremesp.org.br/?siteAcao=Revista\&id=150>. Acesso em: 31 jul 2010.

DUNN, J.J. et al. Patient and house officer attitudes on physician attire and etiquette. JAMA, v.257, n.1, p.65-68, 1987. 
EDITORIAL. The traditional white coat: goodbye, or au revoir? Lancet, v.370, n.9593, p.1102, 2007.

FARRAJ, R.; BARON, J.H. Why do hospital doctors wear white coats? J R Soc Med, v.84, n.1, p.43, 1991.

FISCHER, R.L. et al. Does physician attire influence patient satisfaction in an outpatient obstetrics and gynecology setting? Am. J. Obstet. Gynecol., v.196, n.2, p.186.e1-5, 2007.

FONTANELLA, B.J.B.; RICAS, J.; TURATO, E.R. Amostragem por saturação em pesquisas qualitativas em saúde: contribuições teóricas. Cad Saude Publica, Rio de Janeiro, v.24, p.17-27, 2008.

GJERDINGEN, D.K.; SIMPSON, D.E.; TITUS, S.L. Patients' and physicians' attitudes regarding the physician's professional appearance. Arch. Intern. Med., v.147, n.7, p.1209$1212,1987$.

GLASER, B.G.; STRAUSS, A. The discovery of grounded theory: strategies for qualitative research. New York: Aldine de Gruyter, 1967. 271p.

GOMES, R.; MENDONÇA, E.A. A representação e a experiência da doença: princípios para a pesquisa qualitativa em saúde. In: MINAYO, M.C.S.; DESLANDES, S. (Org.). Caminhos do pensamento: epistemologia e método. Rio de Janeiro: Fiocruz, 2002. p.109-132.

GOODEN, B.R. et al. Hospitalised patients' views on doctors and white coats. Med. J. Aust., v.175, n.4, p.219-222, 2001.

JONES, V.A. The white coat: why not follow suit? JAMA, v.281, n.5, p.478, 1999.

KAZORY, A. Physicians, their appearance, and the white coat. Am. J. Med., v.121, n.9, p.825-828, 2008.

LILL, M.M.; WILKINSON, T.J. Judging a book by its cover: descriptive survey of patients' preferences for doctors' appearance and mode of address. BMJ, v.331, n.7531, p.1524-1527, 2005.

LOH, W.; NG, V.V.; HOLTON, J. Bacterial flora on the white coats of medical students. J. Hosp. Infect., v.45, n.1, p.65-68, 2000.

LOUDON, J.B. Private stress and public ritual. J Psychosom Res, v.10, n.1, p.101-108, 1966. MATSUI, D.; CHO, M.; RIEDER, M.J. Physicians' attire as perceived by young children and their parents: the myth of the white coat syndrome. Pediatr Emerg Care, v.14, n.3, p.198-201, 1998.

MENAHEM, S.; SHVARTZMAN, P. Is our appearance important to our patients? Fam Pract, v.15, n.5, p.391-397, 1998.

MERHY, E.E. Um ensaio sobre o médico e suas valises tecnológicas. Interface: Comunic., Saude, Educ., Botucatu, v.6, p.109-116, 2000. 
MINAYO, M.C.S. O desafio do conhecimento: pesquisa qualitativa em saúde. São Paulo: Hucitec, 1993. 269p

MORSE, J.M.; FIELD, P.A. Qualitative research methods for health professionals. 2 ed. London: Sage, 1995. 254p

NEINSTEIN, L.S.; STEWART, D.; GORDON, N. Effect of physician dress style on patient-physician relationship. J Adolesc Health Care, v.6, n.6, p.456-459, 1985.

TURATO, E.R. Tratado da metodologia da pesquisa clínico-qualitativa: construção teóricoepistemológica, discussão comparada e aplicação nas áreas de saúde e humanas. Petrópolis: Vozes, 2003. 685p

WATSON, D.A.R. What do Australian junior doctors think of white coats? Med Educ, v.36, n.2, p.1209-1213, 2002.

\section{Nota}

${ }^{1}$ B.J.B. Fontanella elaborou o projeto de pesquisa, supervisionou a coleta de dados, realizou a interpretação e discussão dos resultados e participou da redação final do artigo. F.R. Silva coletou os dados, participou da análise e interpretação dos resultados e participou da redação final do artigo. R. Gomes participou da interpretação e discussão dos resultados e da revisão teórica do artigo. 
Rituals and symbols in the formal health care: the case of professional clothing, from the viewpoint of primary care patients

This study aimed to analyze and interpret the thoughts and experiences of service users attending Primary Care / Family Health Units (FHU) on the use of white coat or white clothes by physicians and other health professionals. The method used was interviews with open questions, in depth, with users of FHU, transcribed and analyzed for content and statements. The sample was closed by theoretical saturation. As a result, eleven interviews were identified in a marked asymmetry and psychological and socio-cultural background of the three identified clusters of meaning: clothing as a mark of identity; clothing is not valued as a symbol of professional competence and clothing interferes, positively or negatively, in relations between clinicians and patients. We discuss the urgency of symbolization in health, the difficulties of the participants discuss the topic and why the emergence of possible new symbols of power. Finally, it was concluded that understanding the meanings assigned by users of health systems to the acts and practices carried out by their caregivers may contribute to the progressive refinement of these formal practices of care. Although the functions of ritualistic behaviors and objects used in acts of health care are more easily observed in so-called informal and popular practices, they persist in formal or professional ways of acting. This type of phenomenon occurred after the emergence of modern scientific medicine, with the white coat, for example, and remains at present, although new symbols appear to arise and occupy this ritual space.

> Key words: Professional-patient relationship; doctor-patient relationship; clothing; anthropology; ritualistic behavior. 